\title{
Calibration of Temperature in the Lower Stratosphere from Microwave Measurements Using COSMIC Radio Occultation Data: Preliminary Results
}

\author{
Shu-Peng Ho ${ }^{1,2, *}$, Mitch Goldberg ${ }^{3}$, Ying-Hwa Kuo ${ }^{1,2}$, \\ Cheng-Zhi Zou ${ }^{3}$, and William Schreiner ${ }^{2}$ \\ ${ }^{1}$ National Center for Atmospheric Research, Boulder, CO 80307-3000, USA \\ ${ }^{2}$ University Corporation for Atmospheric Research, Boulder, CO 80307-3000, USA \\ ${ }^{3}$ NOAA/NESDIS/Center for Satellite Applications and Research, 5200 Auth Road, Camp Springs, MD 20746-4304, USA
}

Received 27 June 2007, accepted 6 December 2007

\begin{abstract}
Accurate, consistent, and stable observations from different satellite missions are crucial for climate change detection. In this study, we use Global Positioning System (GPS) Radio Occultation (RO) data from the early phase of the FORMOSAT-3/Constellation Observing System for Meteorology, Ionosphere, and Climate (COSMIC) mission, which was successfully launched on 15 April 2006, to inter-calibrate Temperature in the Lower Stratosphere (TLS) taken from Advanced Microwave Sounding Unit (AMSU) microwave measurements from different satellites for potential improvements of stratospheric temperature trend analysis. Because of the limited number of COSMIC soundings in the early phase of the mission, these results are considered preliminary. In this study, we use COSMIC RO data to simulate microwave brightness temperatures for comparison with AMSU Ch9 measurements (e.g., TLS) on board NOAA15, 16, and 18. Excellent correlation was found between synthetic COSMIC brightness temperatures (Tbs) and Tbs from NOAA15, NOAA16, and NOAA18, respectively. However, systematic differences on the order of 0.7 to $2 \mathrm{~K}$ were found between COSMIC and AMSU observations over Antarctica. Our results demonstrate that synthetic COSMIC Tbs are very useful in identifying inter-satellite offsets among AMSU measurements from different satellites. To demonstrate the long-term stability of GPS RO data, we compare COSMIC dry temperature profiles to those from collocated CHAMP profiles, where CHAMP was launched in 2001. The fact that the CHAMP and COSMIC dry temperature difference between 500 and $10 \mathrm{hPa}$ ranges from $-0.35 \mathrm{~K}$ (at $10 \mathrm{hPa}$ ) to $0.25 \mathrm{~K}($ at $30 \mathrm{hPa}$ ) and their mean difference is about $-0.034 \mathrm{~K}$ demonstrates the long-term stability of GPS RO signals. In order to demonstrate the potential usage of the GPS RO calibrated AMSU Tbs to inter-calibrate other overlapping AMSU Tbs, we examine the uncertainty of the calibration coefficients derived from AMSU-GPS RO pairs. We found the difference between COSMIC calibrated AMSU Tbs and those from CHAMP to be in the range of $\pm 0.07 \mathrm{~K}$ with a $0.1 \mathrm{~K}$ standard deviation. This demonstrates the robustness of the calibration coefficients found from AMSU-GPS RO pairs and shows the potential to use the calibrated AMSU Tbs to calibrate other overlapping AMSU Tbs where no coincident GPS RO data are available.
\end{abstract}

Key words: FORMOSAT-3/COSMIC, Temperature in the Lower Stratosphere, AMSU

Citation: Ho, S. P., M. Goldberg, Y. H. Kuo, C. Z. Zou, and W. Schreiner, 2009: Calibration of temperature in the lower stratosphere from microwave measurements using COSMIC radio occultation data: Preliminary results. Terr. Atmos. Ocean. Sci., 20, 87-100, doi: 10.3319/TAO.2007.12.06.01(F3C)

\section{INTRODUCTION}

Accurate and stable long-term observations of the vertical structure of atmospheric temperature trends are crucial for climate change detection. However, it is not an easy task to construct a consistent temperature record using mea-

\footnotetext{
* Corresponding author

E-mail:spho@ucar.edu
}

surements from different instruments where the characteristics of the instrument may be subsequently modified due to its changing environment. For example, due to the changing instruments, observation practices, and limited spatial coverage, especially over the oceans, it is very difficult to use temperature measurements from radiosondes for climate studies. The estimated trend is sensitive to the 
objective selection of radiosonde samples (Angell 1988; Gaffen et al. 2000; Christy et al. 2003; Christy and Norris 2004; Santer et al. 2005; Sherwood et al. 2005). Measurements from satellite instruments provide continuous observations with a more complete spatial and temporal coverage than that from in situ measurements like radiosondes. Nevertheless, even with absolute calibration against known radiant energy targets before launch, the characteristics of the satellite instrument can still change in response to the extreme environment in space. Due to changing platforms, diurnal cycle sampling and orbital decay, inter-satellite offsets are apparent among similar instruments on board different satellite missions. It is critical to have accurate, consistent, stable, and well-calibrated observations from different satellite missions to improve climate change monitoring.

Since 1978, the National Oceanic and Atmospheric Administration (NOAA) has equipped nine polar satellites (from NOAA6 to NOAA14) with Microwave Sounding Unit (MSU) instruments. MSU, which has four channels with center frequencies in the 50 to $60 \mathrm{GHz}$ oxygen band, can provide atmospheric temperature information near the surface, in the mid-troposphere, upper-troposphere, and stratosphere, respectively, according to its weighting functions. Because MSU measurements are not affected by non-precipitating clouds, MSU measurements provide a very useful atmospheric layered temperature record under nearly all weather conditions (Folland et al. 2001). Starting in 1988, MSU (on board NOAA14) is operating in parallel with the Advanced Microwave Sounding Unit (AMSU). AMSU is on board the NOAA K, L, and M series and contains more channels than the MSU with some of the channels having similar frequencies to those of the MSU. Because of their obvious advantage in terms of global coverage and long-term observations over the past 30 years, MSU and AMSU data have been used widely for atmospheric temperature trend detection (e.g., Spencer and Christy 1992a, b; Christy et al. 1998, 2000, 2003; Mears et al. 2003; Vinnikov and Grody 2003; Fu et al. 2004; Grody et al. 2004; Vinnikov et al. 2006; Zou et al. 2006). However, even with continuous atmospheric-layered temperature observations from combined AMSU and MSU data, inter-satellite biases among different AMSU/MSU datasets are still obvious, due to changing platforms, the effect of the on-orbit heating and cooling of satellite components, and orbit drift errors (Karl et al. 2006). This makes the utilization of AMSU/MSU measurements for climate change detection challenging (see section 2). Therefore, it is important to have an independent dataset, with high accuracy and long-term stability, as a climate benchmark with which to calibrate AMSU/ MSU datasets for the generation of long-term coherent atmospheric temperature records.

GPS RO is the first technique which can provide allweather, high vertical resolution (from $\sim 60 \mathrm{~m}$ near the sur- face to $\sim 1.5 \mathrm{~km}$ at $40 \mathrm{~km}$ ) refractivity profiles (Kursinski et al. 1997; Yunck et al. 2000; Kuo et al. 2004). The fundamental observable of GPS RO is a precise timing measurement that is referenced to ultra-stable atomic clocks on the surface of the Earth. GPS RO data are not affected by weather conditions. Consequently, GPS RO data are ideally suited for use as a climate benchmark data type (Kursinski et al. 1997; Hajj et al. 2004). This was demonstrated by comparing the collocated GPS RO data obtained between Challenging Mini-satellite Payload (CHAMP) (Wickert et al. 2004) and Satélite de Aplicaciones Científicas-C (SAC-C), which showed that the precision of the averaged GPS RO profiles is about $0.1 \mathrm{~K}$ between 10 to $20 \mathrm{~km}$ (Hajj et al. 2004). The precision of $0.1 \mathrm{~K}$ in the average makes GPS RO soundings ideally suited for detecting subtle climate trends. Kuo et al. $(2004,2005)$ have shown that the accuracy of GPS $\mathrm{RO}$ data is comparable to or better than that of radiosondes. Being an active sensor, the GPS RO measurements are not contaminated by persistent clouds, precipitation, and underlying surface conditions, and therefore, are ideally suited for atmospheric climate temperature trend detection (Schroeder et al. 2003; Schmidt et al. 2004; Gobiet et al. 2005).

GPS RO data is also very useful for assessing the quality of other satellite observations for climate studies. By using 49 months of high precision GPS RO data from CHAMP, Ho et al. (2007) characterized the differences of the monthly mean AMSU/MSU temperatures of the lower stratosphere (TLS) between the Remote Sensing Systems (RSS) Inc. (Mears et al. 2003) and University of Alabama in Huntsville (UAH) (Christy et al. 2003) groups where different data merging procedures and different satellite measurements are used as references. However, because CHAMP has only one GPS receiver, it takes more than three months to complete full diurnal coverage once over a region in the low and middle latitudes. Therefore, we may not have enough CHAMP RO observations during this period to determine the small difference in RSS TLS and UAH TLS resulting from different diurnal correction algorithms used by these two groups (Mears et al. 2005). Recently, the six-satellite FORMOSAT-3/Constellation Observing System for Meteorology, Ionosphere, and Climate (COSMIC) mission (denoted as COSMIC hereafter) was successfully launched in April 2006. After the satellites are deployed to operational orbits, $\sim 2500$ GPS RO soundings will be available over the globe every 24 hours (Fig. 1). With very high vertical resolution and accuracy, and about an order of magnitude of more soundings than previously available, with uniformly distributed data in time and space, COSMIC presents a unique opportunity for inter-calibrating the microwave measurements from different satellite missions (see section 3).

The objective of this study is to demonstrate the usefulness of COSMIC data for inter-calibrating measurements from AMSU instruments to potentially improve atmospheric temperature trend analysis. We compare synthetic 
Occultation Locations for COSMIC, 6 S/C, 6 Planes, $24 \mathrm{Hrs}$

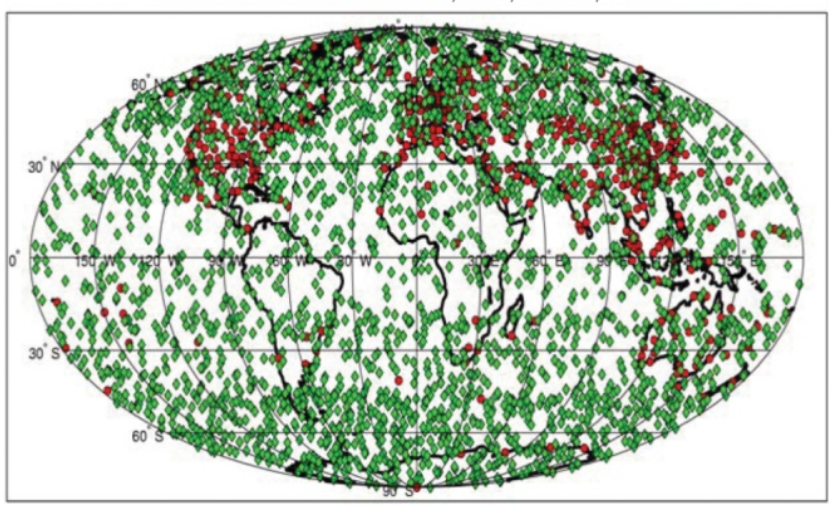

Fig. 1. Typical operational distribution of COSMIC GPS radio occultation soundings (green dots) over a 24-h period across the globe. Red dots are locations of operational radiosonde stations.

COSMIC AMSU Ch9 brightness temperatures (Tbs) to AMSU Tbs from NOAA15 (N15), NOAA16 (N16), and NOAA18 (N18) to show that COSMIC data can be used to inter-calibrate measurements from similar instruments onboard different satellites. The synthetic COSMIC AMSU Ch9 Tbs are computed by applying an AMSU forward model to the COSMIC temperature profiles. To demonstrate the long-term inter-satellite stability of GPS RO data, we collect the collocated dry temperature pairs from CHAMP and COSMIC in September and October 2006. The differences between COSMIC dry temperature profiles and those from CHAMP are examined. To avoid the possible temperature retrieval uncertainty due to the ambiguity of GPS RO refractivity associated with both temperature and moisture in the troposphere, and the effect of ionospheric calibration to the GPS RO refractivity retrievals, we focus on the comparison between GPS RO data and AMSU TLS (e.g., Tb for AMSU Ch9), whose weighting function covers from 300 to $10 \mathrm{hPa}$ (see section 4.1). We illustrate the challenges of using AMSU/MSU measurements to construct coherent temperature records in section 2. The characteristics of GPS RO data from COSMIC are illustrated in section 3. The method to use COSMIC sounding profiles to inter-calibrate AMSU data from different NOAA satellite missions and the comparison results are presented in section 4 . The comparisons of COSMIC dry temperature profiles with those from collocated CHAMP data are also shown in section 4 . The uncertainty of the GPS RO calibrated AMSU Tbs is also examined in this section. We conclude this study in section 5 .

\section{THE CHALLENGES OF USING AMSU/MSU DATA TO CONSTRUCT COHERENT TEMPERATURE RECORDS}

Over the past 15 years, various studies have been performed to determine long-term atmospheric temperature trends using MSU/AMSU measurements. However, the trends derived from these measurements are under significant debate (Karl et al. 2006), with different groups (Christy et al. 2003 from UAH; Mears et al. 2003 from RSS; and Zou et al. 2006 from NESDIS of NOAA) yielding different trends. In general, there are two primary challenges for constructing AMSU/MSU data into consistent long-term temperature records.

(i) On either AM or PM orbits, the equatorial crossing times of the NOAA satellite orbits drift in local time after launch (Fig. 2, derived from N6 to N14). The drift of local time can be as large as eight hours in 12 years (e.g., NOAA 14 from 1995 to 2007). This indicates that the temporal sampling of the MSU/AMSU measurements at specific geographical locations is also changing with time for each NOAA satellite. AMSU/MSU measurements are calibrated against the known warm target on board the NOAA satellites. However, the warm target experiences abnormal changes due to the on orbit heating or cooling of satellite components. To use a microwave instrument to detect climate temperature change, we have to carefully remove calibration drifts that are correlated with the temperature of the calibration target (Christy et al. 2000; Mears et al. 2003; Zou et al. 2006). To remove the on-orbit calibration drift, different empirical and physical correction methods were introduced by different groups (Christy et al. 2000, 2003; Mears et al. 2003; Grody et al. 2004; and Zou et al. 2006).

(ii) Alternately, to construct a long-term homogenous temperature record, one has to calibrate the temperature data using a period of overlap between old measurements and new measurements. When results from supposedly identical satellite instruments are compared, inter-satellite offsets are immediately apparent. A set of the pentad global ocean-averaged inter-satellite offsets for MSU Ch2 for NOAA operational calibration generated by Zou et al. (2006) is reproduced in Table 1. It can be seen in Table 1 that the inter-satellite offsets have a range of a few tenths of degrees varying

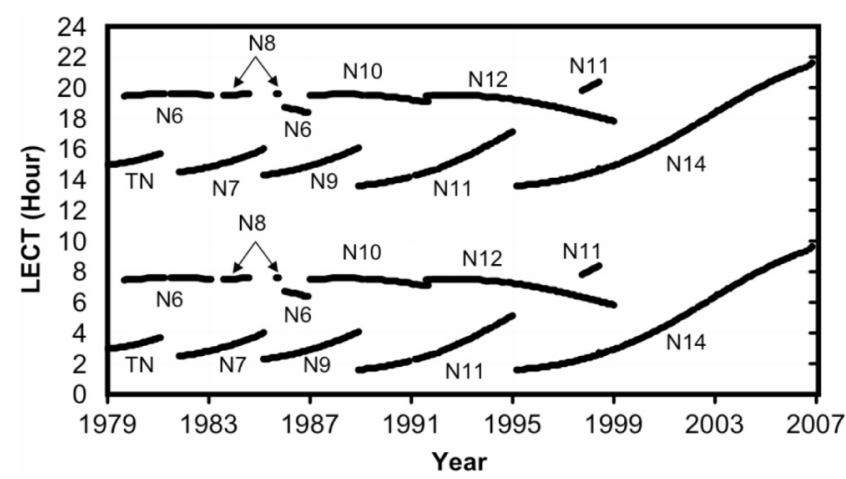

Fig. 2. NOAA satellite orbit drifts with local times after launch from 1978 to 2007 . Numbers in the figure represent satellite series from NOAA6 to NOAA14. 
Table 1. Mean biases of the pentad global ocean-averages for MSU Ch2 between two satellites during their overlap periods.

\begin{tabular}{cccc}
\hline \multicolumn{2}{c}{ Overlapping Satellites } & Overlapping period & Inter-satellite bias \\
J & K & & $-J$ \\
\hline N10 & N11 & $10 / 88-08 / 91$ & $-0.605 \mathrm{~K}$ \\
N10 & N12 & $06 / 91-08 / 91$ & $0.198 \mathrm{~K}$ \\
N11 & N12 & $06 / 91-12 / 94$ & $0.646 \mathrm{~K}$ \\
N12 & N14 & $04 / 95-11 / 98$ & $-0.343 \mathrm{~K}$ \\
\hline
\end{tabular}

from year to year. The inter-satellite offsets also vary for different channels at different locations (not shown). To remove the inter-satellite calibration offsets, different merging procedures were introduced by different groups (Christy et al. 2003; Mears et al. 2003; Zou et al. 2006).

Thus, even beginning with the same raw data, different choices on how to remove non-climate factors as discussed above could lead to different trends. Since the adjustments are complicated and involve expert judgments that are difficult to be evaluated due to a lack of traceable standards, the different temperature trends reported from different groups still present a controversial issue in climate analysis.

In this study, AMSU L1B raw counts for NOAA15, 16, and 18 from September 2006 were downloaded from NESDIS. We used reading software and calibration coefficients for each NOAA AMSU instrument provided by NOAA to convert the raw counts into brightness temperatures. Ancillary data for each AMSU pixel including viewing angle, location, and time were also downloaded with L1B data.

\section{THE CHARACTERISTICS FOR GPS RADIO OCCULTATION DATA FROM COSMIC MISSION}

GPS limb sounding is the first technique which can provide high vertical resolution all-weather measurements. The fundamental observation of the GPS RO is a measurement of the phase and amplitude of the GPS radio signals. With knowledge of the precise positions and velocities of the GPS and Low Earth Orbiting (LEO) satellites, which carry the GPS receiver, we can retrieve a distribution of the bending angles at the ray perigee point (the point of the ray path that is closest to the earth) (Melbourne et al. 1994; Hocke 1997; Rocken et al. 1997; Feng and Herman 1999; Steiner et al. 1999). From the vertical distribution of the bending angle we can derive a vertical profile of atmospheric refractivity, which is a function of atmospheric temperature, moisture and pressure (Ware et al. 1996). The COSMIC mission consists of six micro-satellites. The satellites are currently being deployed to operational orbits and we expect that COSMIC will provide approximately 2500 soundings per day. The uniform temporal and spatial distribution of GPS RO profiles and their long-term stability and high vertical resolution are very important characteristics to the process of inter-calibrating microwave measurements (see below).

Kuo et al. (2004) showed that GPS RO soundings demonstrate a very high accuracy (up to $0.3 \%$ in terms of refractivity) in the atmospheric layer between 5 to $25 \mathrm{~km}$. In a tropical lower troposphere, a complicated vertical structure of humidity usually results in multi-path propagation and a strong phase and amplitude fluctuation of RO signals, which leads to larger uncertainty in the retrieved refractivity below $5 \mathrm{~km}$, based on the traditional signal tracking algorithm (known as the phase lock loop tracking algorithm). Recently, an advanced tracking algorithm, known as open loop tracking, has been developed and tested on the COSMIC satellites. Results show that open-loop tracking algorithm allows much more accurate retrievals of refractivity in the lower troposphere, and can resolve structures associated with the atmospheric boundary layer. About $90 \%$ of the COSMIC data penetrate to around $2 \mathrm{~km}$ height or lower (Sokolovskiy et al. 2006).

The early phase of the COSMIC mission, when these six COSMIC receivers were closely located, provided a unique opportunity to test the precision of GPS RO measurements, where the GPS RO signals travel through nearly the same atmospheric paths. The differences in refractivity between COSMIC RO soundings (from 2006, day 111 through 277) when their tangent points are less than $10 \mathrm{~km}$ apart were compared to provide an estimate of the precision of the GPS RO technique (Schreiner et al. 2007). The results show that the standard deviation of a refractivity difference is around $0.15 \%$ from 8 to $20 \mathrm{~km}$. Here we plot the median and the Median Absolute Deviation (MAD) of a dry temperature (wherein a temperature reading is obtained using refractivity and the hydrostatic equation assuming no water vapor in the atmosphere) from slightly more pairs (from 2006, day 111 through 300) from COSMIC FM3 (Flight Model \#3) and FM4 receivers as shown in Fig. 3. The MAD is smallest from 10 to $20 \mathrm{~km}$, where the mean MAD is about $0.35 \mathrm{~K}$ (Fig. 3a). Since this estimate of precision is derived from the difference of two profiles, the precision for a single profile (assuming Gaussian errors) can be obtained by dividing by 

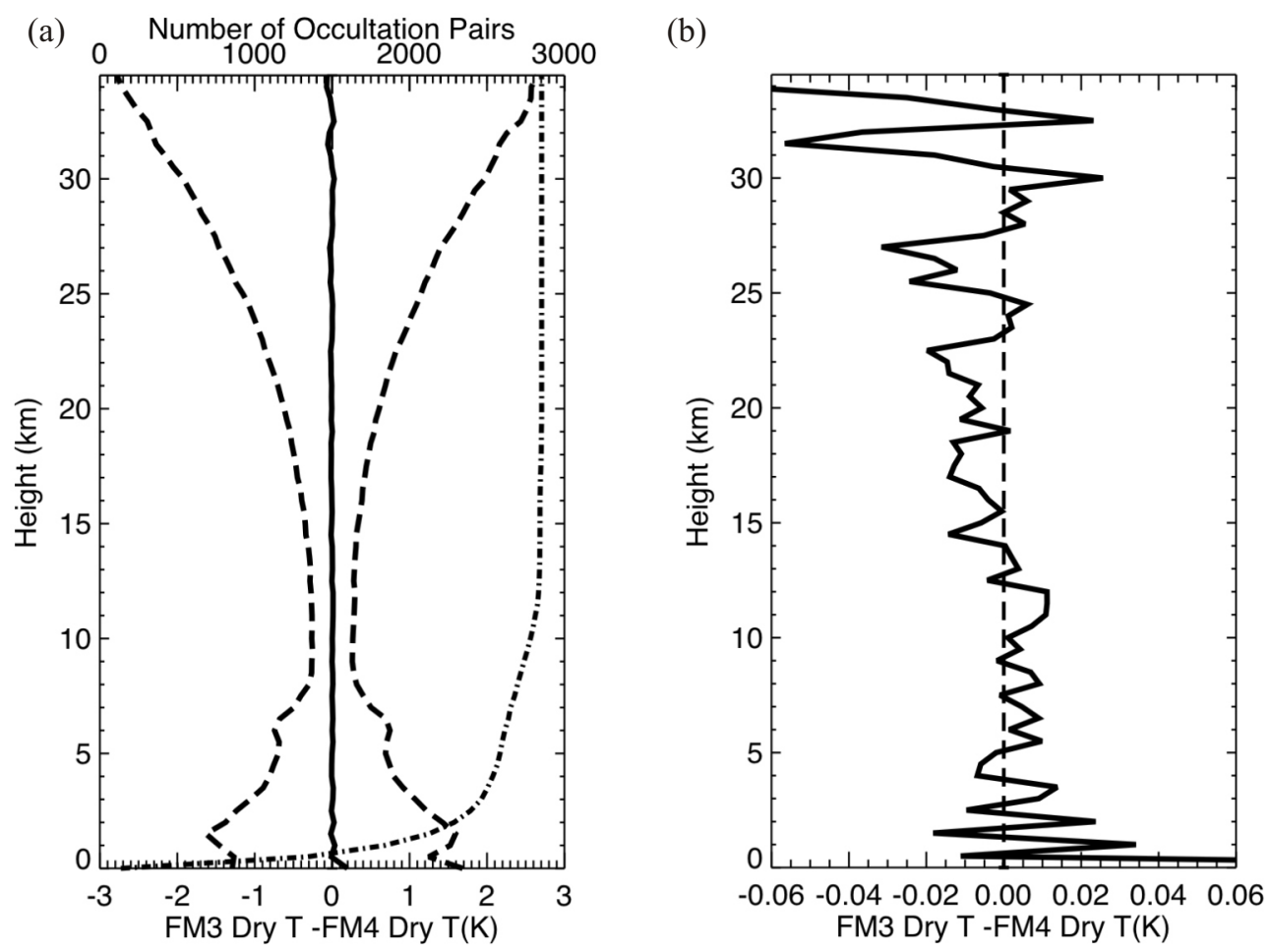

Fig. 3. (a) The median and the median absolute deviation (MAD) of the dry temperature difference between two COSMIC satellites (FM3 and FM4) from 2006, day 111 through 300 where the distance between FM3 - FM4 receivers are within $10 \mathrm{~km}$. The dashed line is MAD to its median difference (in solid line) and the dashed-dotted line is the number of FM3 - FM4 profile pairs used in the comparison at various vertical levels, (b) median of the dry temperature difference between FM3 - FM4 as (a) but in a much smaller temperature scale in $\mathrm{x}$-axis.

sqrt(2), which results in a single dry temperature profile precision of $\sim 0.25 \mathrm{~K}$ between 10 to $20 \mathrm{~km}$. It should be noted that these precision estimates from 10 to $20 \mathrm{~km}$ may still be associated with significant real meteorological variability within $10 \mathrm{~km}$. A larger MAD below $8 \mathrm{~km}$ is related to a larger natural variability within a $10 \mathrm{~km}$ separation of distance and RO tracking errors. The increase of MAD above $25 \mathrm{~km}$ is most likely caused by residual errors of ionospheric corrections. The medians of dry temperature differences are very close to zero from the surface to $35 \mathrm{~km}$ (Figs. 3a and b). The ranges of median values of dry temperature differences from surface to $30 \mathrm{~km}$ are within $0.05 \mathrm{~K}$ (Fig. $3 \mathrm{~b}$ ), where it is as small as $0.02 \mathrm{~K}$ from 3 to $25 \mathrm{~km}$. The median values of dry temperature differences in which $<0.05 \mathrm{~K}$ in the mean make COSMIC RO data ideally suited for monitoring climate trends from the surface to $35 \mathrm{~km}$. The experimental error estimates presented here are similar in magnitude to simulated errors presented by Kursinski et al. (1997). Though not quantifying the common systematic errors in the FM3 - FM4 pairs, results here still demonstrate the quality of COSMIC GPS RO data and their potential to serve as a robust climate benchmark.

In this study, we apply COSMIC RO dry temperature profiles from September 2006 to an AMSU forward model to compute synthetic AMSU Tbs. Collocated dry tempera- ture pairs from CHAMP and COSMIC are also compared. All COSMIC and CHAMP RO dry temperature profiles were downloaded from the UCAR COSMIC Data Analysis and Archive Center (CDAAC) (http://cosmic-io.cosmic.ucar .edu/cdaac/index.html). To avoid water vapor and ionosphere calibration effects on COSMIC dry temperature retrievals, in this study we focus on the comparison of AMSU temperature in the upper troposphere and lower stratosphere (a region from 5 to $30 \mathrm{~km}$, e.g., Tb for AMSU Ch9). Comparison results for AMSU Ch8 and $\mathrm{Ch} 10 \mathrm{Tbs}$ to the synthetic COSMIC Tbs are also included (see below).

\section{USE COSMIC RO SOUNDINGS TO INTER-CALIBRATE AMSU MEASUREMENTS}

\subsection{Calibration Method}

Similar to using defined calibration coefficients for each NOAA AMSU/MSU instrument derived using the warm target on board the satellite and the universe background temperature as the cold target (provided from NOAA to convert AMSU L1B raw counts to brightness temperatures), in this study, we use a synthetic AMSU Tbs calculated from applying a COSMIC temperature profile to an AMSU forward model to inter-calibrate AMSU Tbs for different NOAA satellite missions. The COSMIC data are used as stable 
benchmark targets here. A two-step strategy is implemented.

Step 1: To avoid AMSU vertical weighting function representation errors, instead of using a global fixed weighting function (WF), we apply a COSMIC dry temperature profile to an AMSU fast forward model from the Cooperative Institute for Meteorological Satellite Studies-CIMSS $\left(\mathrm{MWF}_{\mathrm{CIMSS}}\right)$ with 100 fixed pressure levels (Hal Woolf, CIMSS, personal communication 2005; the validation of microwave transmittance of this model is described in Woolf et al. 1999) to compute the synthetic microwave Tbs. Because the shape and the magnitude of AMSU temperature WF is a function of the temperature profile (Fig. 4), this approach is able to reduce WF representation errors in the simulated Tbs as compared to those computed from a globally-fixed WF. The $\mathrm{MWF}_{\mathrm{CIMSS}}$ used here was operationally employed in the International ATOVS Processing Package developed at SSEC, University of Wisconsin. COSMIC RO soundings were interpolated onto the $\mathrm{MWF}_{\mathrm{CIMSS}}$ levels. Since the vertical resolution of the COSMIC profile is from $60 \mathrm{~m}$ near surface to $1.5 \mathrm{~km}$ (Kuo et al. 2004) at higher levels (the raw COSMIC data contain more than 3000 vertical grids for each profile), which is much higher than the $\mathrm{MWF}_{\mathrm{CIMSS}}$ pressure resolution, this approach is unlikely to cause an un-representative error on the vertical grid. Because the shape and magnitude of AMSU temperature WF is also a

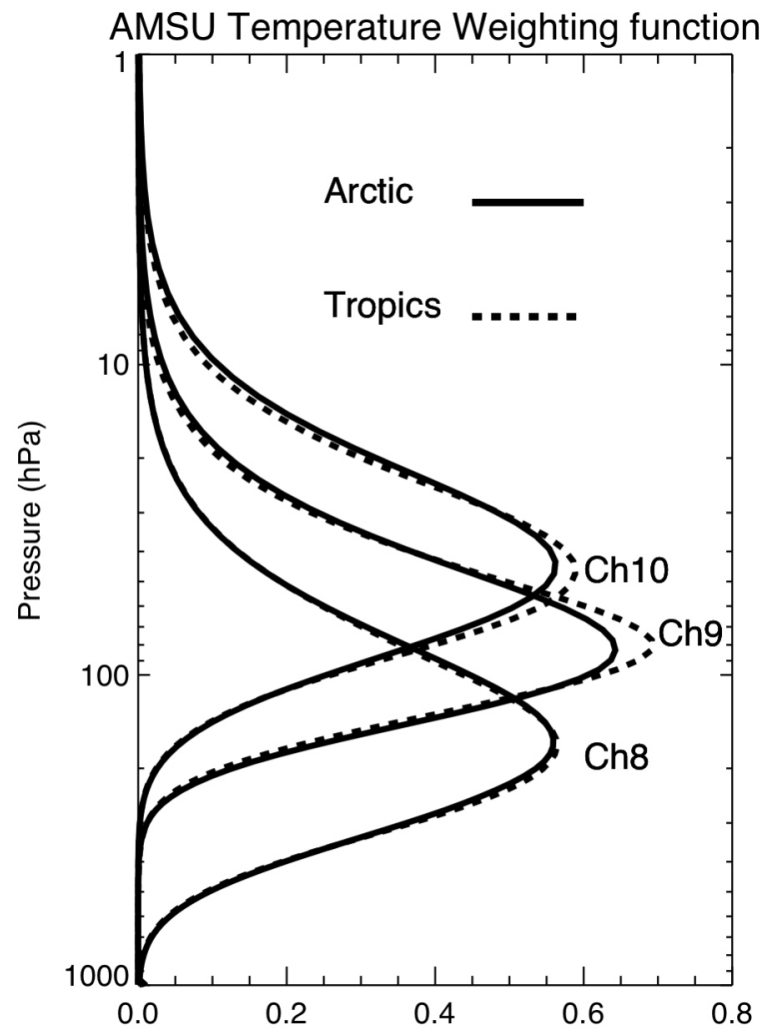

Fig. 4. AMSU Channel 8, 9, and 10 atmospheric weighting functions for a typical atmospheric profile in the Tropics and the Arctic, respectively. The weighting function is defined as $-\mathrm{d}(\operatorname{transmittance}) / \mathrm{d} \ln (\mathrm{p})$. function of viewing geometry, the satellite viewing angle is set to nadir for our calculations.

Step 2: To avoid spatial and temporal representation errors, we compute the mean of AMSU Tbs that are collocated with each COSMIC profile within 30 minutes and $50 \mathrm{~km}$. The collocated mean AMSU Tbs from N15 (Tb ThSU $\left._{\text {N15 }}\right)$, $\mathrm{N} 16\left(\mathrm{~Tb}_{\mathrm{AMSU}} \mathrm{N} 16\right)$, and N18 $\left(\mathrm{Tb}_{\mathrm{AMSU}} \mathrm{N}_{18}\right)$ are paired with COSMIC synthetic AMSU Tb ( $\mathrm{Tb}_{\text {COSMIC }}$ ) for N15, N16, and $\mathrm{N} 18$, respectively. AMSU pixels with a satellite viewing angle ranging from -15 to 15 degrees are all included in this study to increase the number of AMSU pixels in our comparison. This approach is unlikely to cause a bias in the analysis, as it is just a random effect at each AMSU-COSMIC pair. Although not fully deployed to their final orbits, relatively uniformly distributed COSMIC profiles shall provide much better temporal and spatial coverage than those from CHAMP.

\subsection{Using COSMIC Data to Inter-Calibrate AMSU Measurements for Different Satellite Missions}

To demonstrate the usefulness of COSMIC data to inter-calibrate measurements from similar instruments but onboard different satellites, we compare COSMIC synthetic AMSU Tbs to AMSU Tbs from N15 and N16 and N18. COSMIC synthetic AMSU Tbs are derived from applying COSMIC dry temperature profiles to $\mathrm{MWF}_{\mathrm{CIMSS}}$ (as described in section 4.1). The atmospheric contribution for AMSU Ch9 is from the upper troposphere to the lower stratosphere (Fig. 4). The collocated AMSU Ch9 Tbs from $\mathrm{N} 15$, N16, and $\mathrm{N} 18\left(\mathrm{~Tb}_{\mathrm{AMSU} \_\mathrm{N} 15}, \mathrm{~Tb}_{\mathrm{AMSU} \_\mathrm{N} 16}\right.$, and Tb $\left.\mathrm{Tb}_{\mathrm{AMSU}} \mathrm{N}_{18}\right)$ within 30 minutes and $50 \mathrm{~km}$ of COSMIC profiles are collected and compared to $\mathrm{Tb}_{\text {COSMIC N15 }}$ (Fig. 5a), Tb $\mathrm{C}_{\text {COSMIC N16 }}$ (Fig. 5b), and $\mathrm{Tb}_{\mathrm{COSMIC}} \mathrm{N}_{18}$ (Fig. $5 \mathrm{c}$ ), respectively. The facts that the paired COSMIC synthetic AMSU Tbs are highly correlated with that from $\mathrm{Tb}_{\mathrm{AMSU}} \mathrm{N} 15$ (correlation coefficient $=0.99), \mathrm{Tb}_{\mathrm{AMSU} \mathrm{N} 16}$ (correlation coefficient $\left.=0.99\right)$ and $\mathrm{Tb}_{\mathrm{AMSU}} \mathrm{N} 18_{\text {(correlation coefficient }}=0.998$ ) and with small standard deviation to their means of COSMIC-N15 (0.9 K), COSMIC-N16 $(0.84 \mathrm{~K})$, and COSMIC-N18 $(0.95 \mathrm{~K})$ pairs, demonstrate the usefulness of COSMIC data to inter-calibrate $\mathrm{Tb}_{\mathrm{AMSU} \_\mathrm{N} 15}, \mathrm{~Tb}_{\mathrm{AMSU} \_\mathrm{N} 16}$, and $\mathrm{Tb}_{\mathrm{AMSU} \_\mathrm{N} 18}$ to the synthetic COSMIC Tbs despite their different orbits, orbit drift errors and sensor acuity decaying over time.

There are obvious mean differences among COSMIC$\mathrm{N} 15$ (N15-COSMIC $=-0.42 \mathrm{~K}$ ), COSMIC-N16 (N16-COS$\mathrm{MIC}=-0.83 \mathrm{~K})$ and COSMIC-N18 $(\mathrm{N} 18-\mathrm{COSMIC}=-1.13 \mathrm{~K})$ pairs. The tight fit between COSMIC-N15, COSMIC-N16 and COSMIC-N18 pairs shows that the COSMIC synthetic AMSU Tbs can identify the small inter-satellite offsets among N15, N16, and N18 Tbs, which are orbit- and location-dependent. In Figs. 5a, b, and c, we use different colors to indicate the pixel pairs from different latitudinal zones. In Fig. 5, the higher Tb values (in black) are from the North 

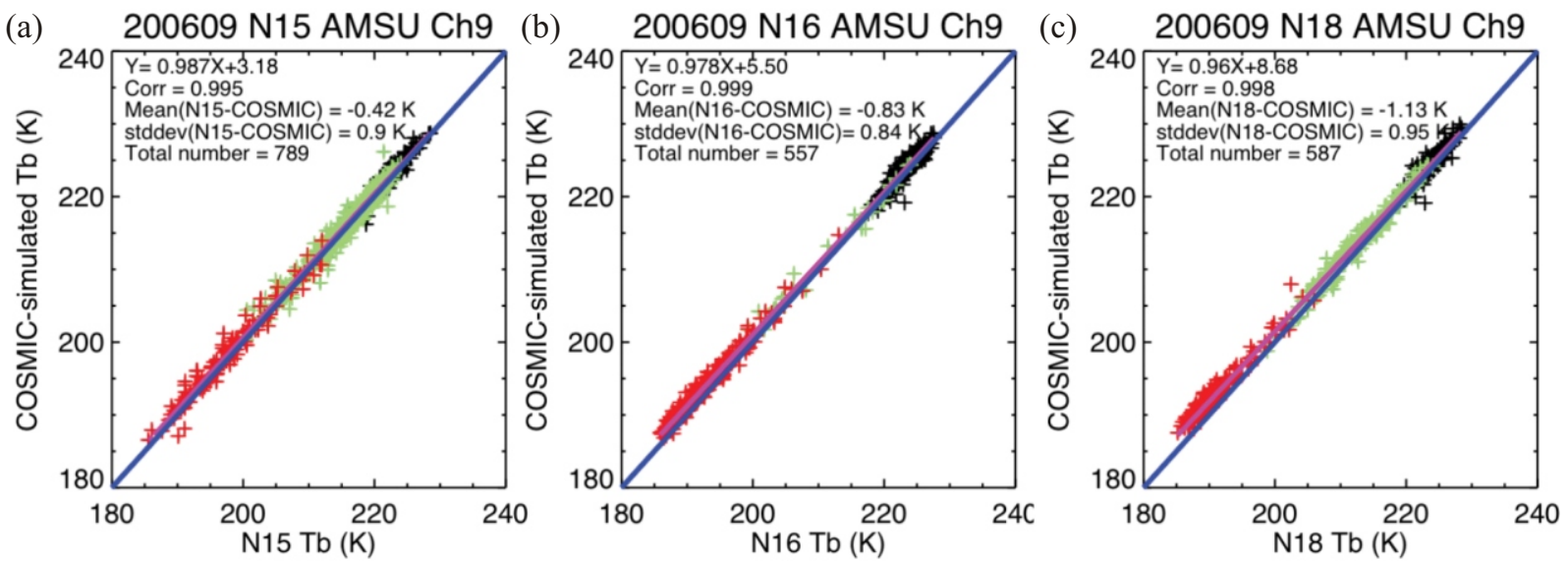

Fig. 5. Comparison of COSMIC-simulated AMSU Ch9 Tbs and (a) NOAA 15 AMSU Ch9 Tbs and (b) NOAA 16 AMSU Ch9 Tbs and (c) NOAA 18 AMSU Ch9 Tbs for September 2006. Pixels in red are from the $60-90^{\circ} \mathrm{S}$ zone, pixels in green are from $60^{\circ} \mathrm{N}-60^{\circ} \mathrm{S}$ zone, and pixels in black are from $60-90^{\circ} \mathrm{N}$ zone.

Pole regions $\left(60-90^{\circ} \mathrm{N}\right.$ zone during the northern hemispheric summer) and the lower $\mathrm{Tb}$ values (in red) are from the South Pole regions $\left(60-90^{\circ} \mathrm{S}\right.$ zone during the southern hemispheric winter). The Tb values in between (in green) are from mid-latitudes and the tropics $\left(60^{\circ} \mathrm{S}-60^{\circ} \mathrm{N}\right.$ zone). The mean biases of NOAA-COSMIC pairs for different latitudinal zones are shown in Table 2. As described in section 2, inter-satellite offsets among NOAA AMSU/MSU measurements vary with year, local time, and location. The mean biases of NOAA-COSMIC pairs at different latitudinal zones found here (Table 2) are consistent with the mean biases of RSS-CHAMP pairs found by Ho et al. (2007, Table 1) where AMSU Ch9 Tb from RSS is systematically 0.8 to $1.9 \mathrm{~K}$ lower than that derived from CHAMP (Tb CHAMP $)$ at almost all latitudinal zones.

It can be seen in Table 2 and Fig. 5 that $\mathrm{Tb}_{\mathrm{Amsu}} \mathrm{N}_{16}$ and $\mathrm{Tb}_{\mathrm{AMSU} \mathrm{N} 18}$ in the South Pole regions are biased 1 to $2 \mathrm{~K}$ lower than that from COSMIC, where the Tb $\mathrm{AMSU}_{\mathrm{N} 16}$ and $\mathrm{Tb}_{\mathrm{AMSU}} \mathrm{N18}$ in the South Pole regions are biased only about $0.5 \mathrm{~K}$ lower than that from COSMIC during the southern hemisphere summer (e.g., for February 2007, not shown). The cause of the large NOAA-COSMIC Tbs biases in the southern hemisphere during the winter is probably not due to the uncertainty of GPS RO data. We have examined the re-

Table 2. Mean biases of N15-COSMIC, N16-COSMIC, and N18COSMIC TLS for $60-90^{\circ} \mathrm{S}$ zone, $60^{\circ} \mathrm{N}-60^{\circ} \mathrm{S}$ zone, and $60-90^{\circ} \mathrm{N}$ zone.

\begin{tabular}{lccc}
\hline & $\mathbf{6 0}^{\circ} \mathbf{N}-\mathbf{9 0}^{\circ} \mathbf{N}$ & $\mathbf{6 0}^{\circ} \mathbf{N}-\mathbf{6 0}^{\circ} \mathbf{S}$ & $\mathbf{6 0}^{\circ} \mathbf{S}-\mathbf{9 0}^{\circ} \mathbf{S}$ \\
\hline N15-COSMIC & $-0.47 \mathrm{~K}$ & $-0.34 \mathrm{~K}$ & $-0.67 \mathrm{~K}$ \\
N16-COSMIC & $-0.54 \mathrm{~K}$ & $-0.68 \mathrm{~K}$ & $-1.2 \mathrm{~K}$ \\
N18-COSMIC & $-0.81 \mathrm{~K}$ & $-0.86 \mathrm{~K}$ & $-1.92 \mathrm{~K}$ \\
\hline
\end{tabular}

sidual errors of the ionospheric calibration and the possible topography effect on COSMIC data over Antarctica. Because the atmospheric contribution for AMSU Ch9 $\mathrm{Tb}$ is mainly from 10 to $300 \mathrm{hPa}$ (see AMSU Ch9 WF in Fig. 4), the impact of any uncertainty with regard to ionospheric corrections and Antarctica topography on the synthetic COSMIC Tbs is minimal. In addition, we have also compared the synthetic AMSU Ch9 Tb derived from CHAMP dry temperature $\left(\mathrm{Tb}_{\mathrm{CHAMP}}\right)$ with that derived from the temperature profiles from ECMWF $\left(\mathrm{Tb}_{\mathrm{ECMWF}}\right)$ in the southern hemisphere during the winter. Lower vertical resolution ECMWF profiles ( $<30$ vertical levels) are used here. Due to a lack of high vertical resolution observations to resolve the sharp temperature inversion near the tropopause, ECMWF temperature is biased lower as compared to CHAMP near the upper troposphere and lower stratosphere (the bias decreased when high vertical resolution, 91 levels, ECMWF profiles are used). Therefore, the $\mathrm{Tb}_{\mathrm{ECMWF}}$ is biased $0.67 \mathrm{~K}$ lower than $\mathrm{Tb}_{\mathrm{CHAMP}}$, which still cannot explain the cause of the large NOAA-COSMIC Tbs biases in the southern hemisphere during the winter. Note that because the quality of the GPS RO data do not vary with different orbits, the different slopes and biases among NOAA-COSMIC pairs in Fig. 5 generally occur because of orbit drift errors and sensor acuities decaying from the AMSU data on board different NOAA satellites. Since the AMSU data use pre-launch calibration coefficients, which may not account for the nonlinear calibration effect (Zou et al. 2006), temperaturedependent biases for AMSU Tbs may be possible. More investigations regarding the causes for the larger biases between the AMSU and COSMIC observations over Antarctica during the southern hemispheric winter will be pursued in a future study. The GPS RO data will then be compared to the new AMSU data from NESDIS, where the nonlinear calibration coefficients are applied (Zou et al. 2006). 
Here we also explore the feasibility of using GPS RO data to inter-calibrate AMSU Ch8 and Ch10 Tbs, whose atmospheric contribution is also mainly within 5 to $30 \mathrm{~km}$. The comparisons of N15, N16, and N18 Ch8 and Ch10 Tbs, whose weighting functions are given in Fig. 4, to the corresponding synthetic COSMIC Tbs using the calibration procedure discussed in section 4.1, are shown in Fig. 6. Only subsets of that from Fig. 5 are used here. Most of COSMIC-NOAA pairs in Fig. 6 are over the polar regions where water vapor content above $500 \mathrm{hPa}$ is negligible. Because a very small portion of AMSU Ch8 and Ch10 WFs are covering above $10 \mathrm{hPa}$ (for AMSU Ch10) and below $500 \mathrm{hPa}$ (for AMSU Ch8), the effect of the uncertainty of GPS RO dry temperature below $500 \mathrm{hPa}$ to the synthetic AMSU Tbs is small. The COSMIC synthetic AMSU Ch8 and Ch10 Tbs are very close to those from AMSU Tbs. The excellent agreement and small variations between AMSU Ch8 Tbs and Ch10 Tbs from N15, N16, and N18 and those from synthetic COSMIC Tbs also demonstrates the potential to use COSMIC data to inter-calibrate AMSU Ch8 and Ch10 Tbs.

\subsection{The Stability of GPS RO Data}

Because the sensitivity of a satellite receiver for infrared and microwave instruments may decay in space after launch, it is critically important to have independent observations with long-term stability as climate benchmarks in which measurements from either newly-launched or aging instruments can all refer. For temperature trends constructed from AMSU/MSU measurements, where there is no climate ben-
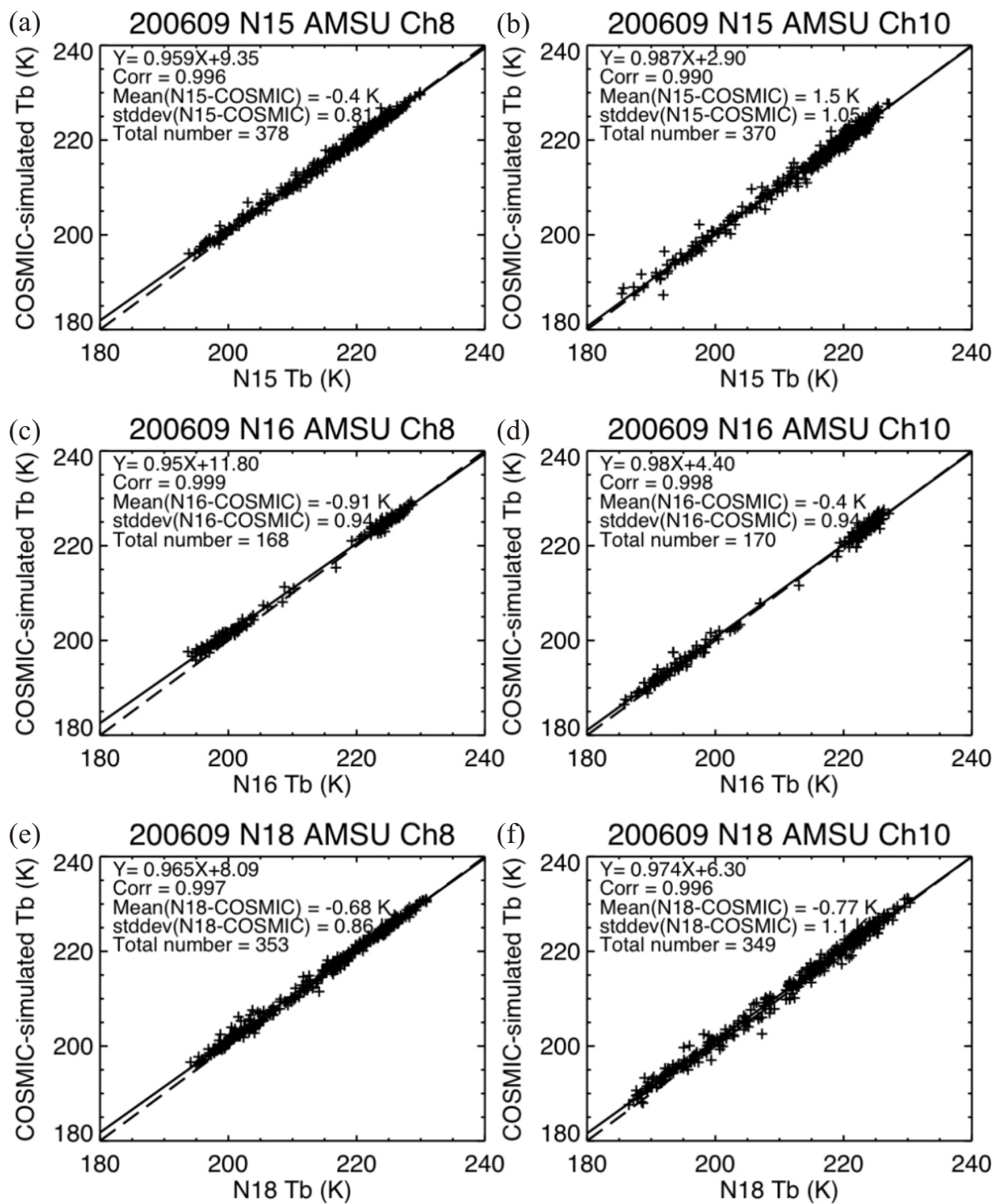

Fig. 6. Comparison of (a) COSMIC-simulated AMSU Ch8 Tbs and NOAA 15 AMSU Ch8 Tbs, (b) COSMIC-simulated AMSU Ch10 Tbs and NOAA 15 AMSU Ch10 Tbs, (c) COSMIC-simulated AMSU Ch8 Tbs and NOAA 16 AMSU Ch8 Tbs, (d) COSMIC-simulated AMSU Ch10 Tbs and NOAA 16 AMSU Ch10 Tbs, (e) COSMIC-simulated AMSU Ch8 Tbs and NOAA 18 AMSU Ch8 Tbs, (f) COSMIC-simulated AMSU Ch10 Tbs and NOAA 18 AMSU Ch10 Tbs. 
chmark reference for correcting the inter-satellite bias, the temperature trends can vary as much as $0.1 \mathrm{~K} /$ decade when different satellite measurements are used as references (Christy et al. 2003). Here we investigate the stability of GPS RO data by comparing dry temperature profiles from COSMIC to those from collocated CHAMP profiles. The same software packages are used in COSMIC CDAAC to process the real time COSMIC and CHAMP data. To include more COSMIC and CHAMP pairs, here we used COSMIC and CHAMP pairs collocated within $200 \mathrm{~km}$ and 1.5 hours collected from 1 September to 31 October 2006, but within $60^{\circ} \mathrm{S}$ to $60^{\circ} \mathrm{N}$, in our comparison. Around 80 COSMIC and CHAMP pairs are included here (Fig. 7). Because of the large time and separation distance ranges used here and the fact that the ray path for CHAMP and COSMIC pairs may have significantly different azimuth angles, the standard deviation to the mean dry temperature differences between COSMIC and CHAMP pairs is relatively large in the midtroposphere $(\sim 2 \mathrm{~K})$ and above $50 \mathrm{hPa}(\sim 3-4 \mathrm{~K})$. Because different signal tracking algorithms are used by CHAMP (phase lock loop tracking) and COSMIC (open loop tracking), which allows much more accurate retrievals of the COSMIC refractivity in the lower troposphere than for

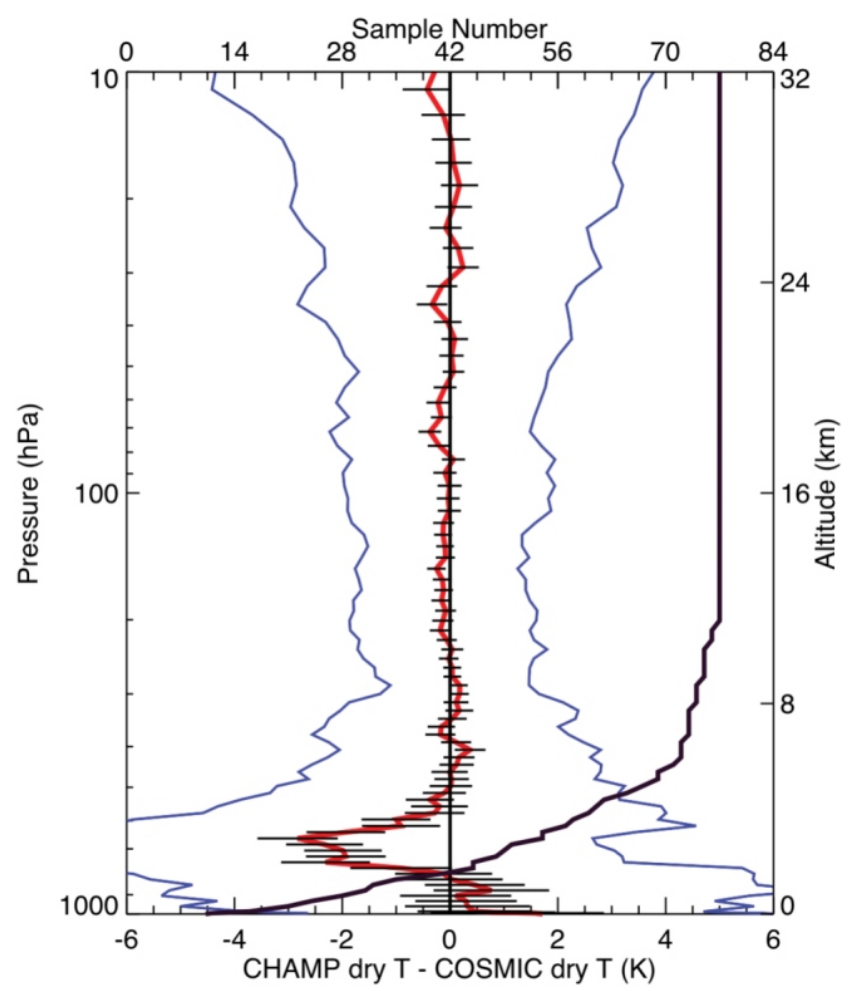

Fig. 7. Comparison statistics (mean: red; standard error of the mean: horizontal black lines superimposed on the mean; standard deviation: blue; sample number of compared soundings: solid black line) of 80 CHAMP and COSMIC profiles that were collocated within $200 \mathrm{~km}$ and 90 minutes within $60^{\circ} \mathrm{N}$ and $60^{\circ} \mathrm{S}$ and between 1 September and 31 October 2006.
CHAMP, larger biases between COSMIC and CHAMP are found below $500 \mathrm{hPa}$. Although CHAMP has been in orbit since June 2001 and COSMIC had been in orbit for just five months as of September 2006, the fact that the mean dry temperature difference in the height ranging from 500 to $10 \mathrm{hPa}$ is within the normalized standard error of the mean difference demonstrates long term stability of the GPS RO signals (e.g., GPS RO dry temperature from CHAMP is still consistent with that from new launched COSMIC). The CHAMP and COSMIC dry temperature difference between 500 and $10 \mathrm{hPa}$ ranges from $-0.35 \mathrm{~K}$ (at $10 \mathrm{hPa}$ ) to $0.25 \mathrm{~K}$ (at $30 \mathrm{hPa}$ ) and their mean difference is about $-0.034 \mathrm{~K}$. Note that, because COSMIC satellites are not fully deployed to operational orbits during the early stage of its mission, and even with a relatively weak constraint (COSMIC-CHAMP pairs collocated within $200 \mathrm{~km}$ and 1.5 hours), we have found only about 80 COSMIC-CHAMP pairs within two months and between $60^{\circ} \mathrm{S}$ to $60^{\circ} \mathrm{N}$ for our comparisons (Fig. 7). To avoid the possibly large sampling errors (mismatch of time and location) between COSMIC and CHAMP data due to the weaker collocation criterion used here, in next section, we present an indirect estimate of the precision of the COSMIC and CHAMP data where N18/N16 Tbs are used as cross references. N16 and N18 AMSU pixels within 30 minutes and $50 \mathrm{~km}$ of COSMIC and CHAMP profiles are collected. Comparison results are shown in section 4.4. In the near future, we will use more COSMIC-CHAMP pairs to confirm the mission independent stability of GPS RO data.

\subsection{The Uncertainty of GPS RO Calibrated AMSU Measurements}

In section 4.2 we have demonstrated the usefulness of COSMIC data to inter-calibrate N15, N16, and N18 AMSU Tbs to the synthetic COSMIC Tbs. This also suggests that the COSMIC calibrated AMSU Tbs may be used as climate benchmarks to calibrate other AMSU Tbs from different satellites whenever they are overlapped. Before using the calibrated AMSU Tbs to calibrate other overlapping measurements, we will need to first examine the robustness of the calibration coefficients (slope and offset) we defined.

In this section, we quantify the accuracy of the defined slope and offset by finding the difference between COSMIC calibrated N18 AMSU Tbs (Tb COSMIC_N18 $_{\text {N }}$ ) and CHAMP ca-

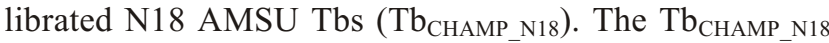
was found by comparing synthetic CHAMP Tbs $\left(\mathrm{Tb}_{\mathrm{CHAMP}}\right)$ to the collocated $\mathrm{Tb}_{\mathrm{AMSU}} \mathrm{N} 18$ using the procedures introduced in section 4.1. Again, CHAMP, COSMIC, N16 and N18 AMSU data from September 2006 are used. The scatter plot for the CHAMP-N18 Tb comparison is shown in Fig. 8a and the slope and offset of the CHAMP-N18 pairs is defined. 
(a) NOAA 18 AMSU Ch9

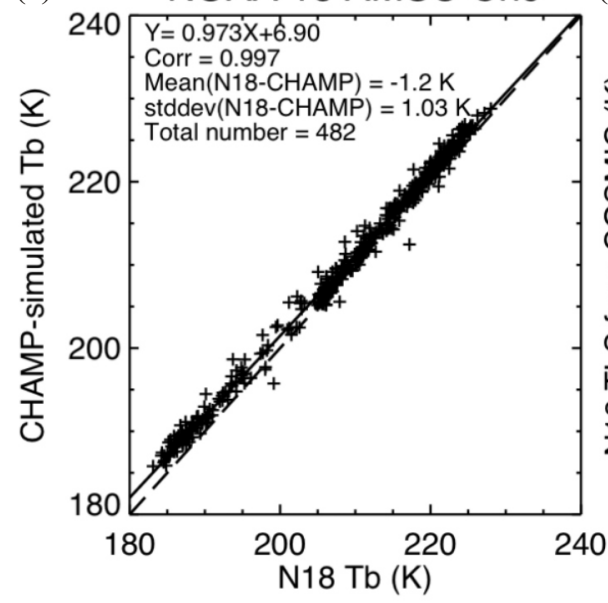

(c)

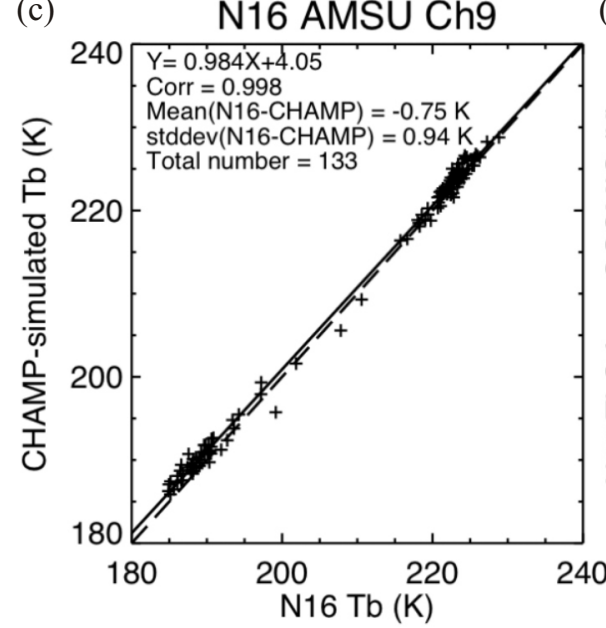

(b) Calibrated N18 TLS

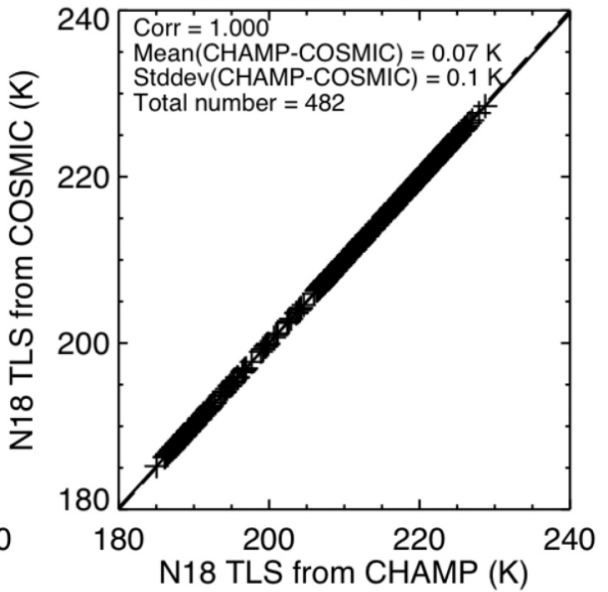

(d) Calibrated N16 TLS

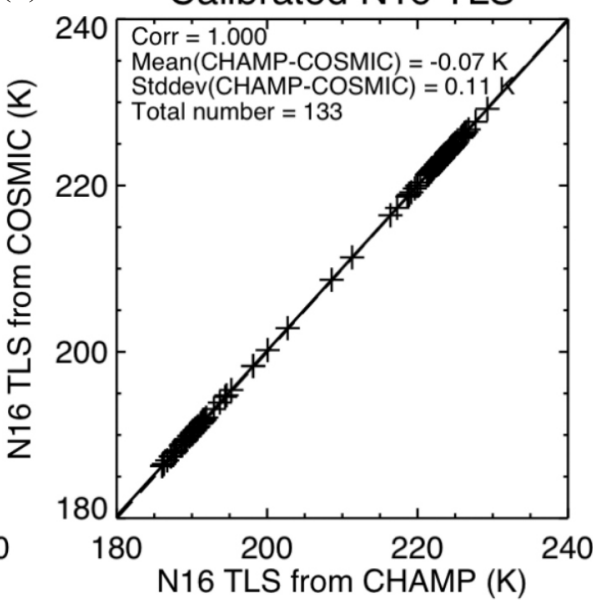

Fig. 8. Comparison of (a) synthetic CHAMP Tbs and AMSU N18 Ch9 Tbs, (b) COSMIC calibrated N18 AMSU Tbs and CHAMP calibrated N18 AMSU Tbs, (c) synthetic CHAMP Tbs and AMSU N16 Ch9 Tbs, and (d) COSMIC calibrated N16 AMSU Tbs and CHAMP calibrated N16 AMSU Tbs.

The $\mathrm{Tb}_{\text {CHAMP_N18 }}$ and $\mathrm{Tb}_{\text {COSMIC_N18 }}$ can be then computed using the following equations when N18 Tbs from CHAMPN18 pairs are used as inputs:

$$
\begin{aligned}
\mathrm{Tb}_{\text {CHAMP_N18 }} & =0.973 \times \mathrm{Tb}_{\mathrm{AMSU} \_\mathrm{N} 18}+6.90 \\
\mathrm{~Tb}_{\text {COSMIC_N18 }} & =0.96 \times \mathrm{Tb}_{\text {AMSU_N18 }}+8.68
\end{aligned}
$$

The slope and offset defined in Eq. (2) are found using COSMIC-N18 pairs (Fig. 5c). Then we apply the same N18 Tbs from CHAMP-N18 pairs to Eqs. (1) and (2) to find $\mathrm{Tb}_{\text {COSMIC_N18 }}$ and $\mathrm{Tb}_{\text {CHAMP_N18. Therefore, by finding the }}$ difference between $\mathrm{Tb}_{\text {COSMIC_N18 }}$ and $\mathrm{Tb}_{\mathrm{CHAMP} N \mathrm{~N} 18}$, we can determine if the slope and offset in Eq. (2) are still valid when different N18 Tbs are used as inputs. The scatter plot of $\mathrm{Tb}_{\text {COSMIC_N18 }}$ and $\mathrm{Tb}_{\text {CHAMP_N18 }}$ is shown in Fig. $8 \mathrm{~b}$. The correlation coefficient of $\mathrm{Tb}_{\text {CHAMP_N18 }}$ and $\mathrm{Tb}_{\text {COSMIC_N18 }}$ is equal to 1.0 and the mean bias between $\mathrm{Tb}_{\mathrm{COSMIC}} \mathrm{N} 18$ and $\mathrm{Tb}_{\text {CHAMP_N18 }}$ is very close to zero $(\sim 0.07 \mathrm{~K})$. The very tight fit of $\mathrm{Tb}_{\text {COSMIC_N18 }}$ and $\mathrm{Tb}_{\text {CHAMP_N18 }}$ (the standard deviation is about $0.1 \mathrm{~K}$ ) demonstrates the consistency between the slope and offset (calibration coefficients) found in the N18-CHAMP pairs and that from N18-COSMIC pairs.

To see if we can find a similar conclusion for the GPS RO calibrated AMSU Tbs from other NOAA satellites, we repeat the above procedures but replace $\mathrm{Tb}_{\mathrm{AMSU} \_\mathrm{N} 18}$ with $\mathrm{Tb}_{\mathrm{AMSU} \_\mathrm{N} 16}$, where COSMIC calibrated N16 AMSU Tbs (Tb COSMIC N16) $_{\text {C }}$ and CHAMP calibrated N16 AMSU Tbs (Tb CHAMP_N16) $_{\text {Can }}$ be computed using the following equations when the same N16 Tbs from CHAMP-N16 pairs are used as inputs:

$\mathrm{Tb}_{\text {CHAMP_N16 }}=0.984 \times \mathrm{Tb}_{\text {AMSU_N16 }}+4.05$

and

$\mathrm{Tb}_{\text {COSMIC_N16 }}=0.978 \times \mathrm{Tb}_{\text {AMSU_N16 }}+5.50$

The scatter plots similar to Figs. $8 \mathrm{a}$ and b are shown in 
Figs. 8c and d, respectively. It is shown in Fig. 8c that we have fewer N16-CHAMP pairs when compared to that of N18-CHAMP pairs (Fig. 8a). This is because the distribution of CHAMP data is more synchronized to that of N18 than that of N16 in this month. The fact that the mean difference $(-0.07 \mathrm{~K})$ and standard deviation $(\sim 0.1 \mathrm{~K})$ between $\mathrm{Tb}_{\text {COSMIC_N16 }}$ and $\mathrm{Tb}_{\text {CHAMP_N16 }}$ is compatible to those from $\mathrm{Tb}_{\text {COSMIC_N18 }}$ and $\mathrm{Tb}_{\text {CHAMP_N18 }}$ demonstrates that even with fewer samples (from CHAMP-N16 pairs in this month), because of the high precision of GPS RO data, we can still define robust slopes and offsets for NOAA-CHAMP pairs which are consistent with those derived from NOAACOSMIC pairs.

Results in Figs. 8b and d can also be interpreted as an indirect estimate of the precision of the averaged $\mathrm{Tb}_{\mathrm{COSMIC}}$ and $\mathrm{Tb}_{\text {Снамр }}$ where $\mathrm{N} 18 / \mathrm{N} 16$ Tbs are used as cross references, although different N18/N16 samples are used for N18/N16-CHAMP and N18/N16-COSMIC pairs. This indicates that, even though we cannot directly compare $\mathrm{Tb}_{\mathrm{COSMIC}}$ and $\mathrm{Tb}_{\mathrm{CHAMP}}$, by comparing $\mathrm{Tb}_{\text {COSMIC_AMSU }}$ and $\mathrm{Tb}_{\text {CHAMP_AMSU}}$, where slopes and offsets from N18-COSMIC and N18CHAMP pairs respectively are used, we can still define the precision between $\mathrm{Tb}_{\text {COSMIC }}$ and $\mathrm{Tb}_{\text {CHAMP. }}$. The $\pm 0.07 \mathrm{~K}$ mean differences of GPS RO-NOAA pairs and $\sim 0.1 \mathrm{~K}$ of standard deviation may still be related to the natural variability within $50 \mathrm{~km}$ separation distance and 30-minute time difference. In the future, more samples with a smaller time difference and separation distance will be used to provide better estimation of the mean difference and precision between $\mathrm{Tb}_{\text {COSMIC }}$ and $\mathrm{Tb}_{\text {CHAMp. }}$ A smaller mean bias and a higher precision between $\mathrm{Tb}_{\text {COSMIC }}$ and $\mathrm{Tb}_{\text {CHAMP }}$ can be expected.

\section{CONCLUSIONS AND FUTURE WORK}

It is extremely important to have consistent and longterm stable observations from different satellite missions for climate change detection. In this study, we use limited GPS RO data from the early phase of the COSMIC mission to demonstrate the potential usefulness of GPS RO data to inter-calibrate microwave measurements from similar instruments but onboard different satellites. The conclusions we can draw from this study are:

1. Results found in this paper demonstrate the usefulness of COSMIC data to inter-calibrate AMSU Ch9 Tbs from N15, N16, and N18 into coherent lower stratospheric temperature measurements. We compare synthetic AMSU brightness temperatures calculated from the forward model $\mathrm{MWF}_{\text {CIMSS }}$ based on COSMIC dry temperature profiles to AMSU Tbs from N15, N16, and N18. Good agreement was found between synthetic COSMIC brightness temperatures $\left(\mathrm{Tb}_{\text {Cosmic }}\right)$ and those of N15, N16, and N18, respectively. The tight fits from COS-
MIC-N15, COSMIC-N16, and COSMIC-N18 pairs reveal that even with different orbits, orbit drift errors, and sensor sensitivity decaying over time, AMSU measurements, in this case from N15, N16, and N18, can be calibrated to the same reference using the synthetic COSMIC Tbs.

2. We also show that COSMIC data can identify inter-satellite offsets from AMSU measurements from different NOAA satellites. Using uniformly distributed COSMIC data, the global mean differences between COSMICN15 (N15-COSMIC $=-0.42 \mathrm{~K})$, COSMIC-N16 (N16COSMIC $=-0.83 \mathrm{~K})$, and COSMIC-N18 (N18-COS$\mathrm{MIC}=-1.13 \mathrm{~K}$ ) pairs are found. The mean biases between NOAA-COSMIC pairs for different latitudinal zones are also identified, where the largest NOAACOSMIC Tb biases are in the South Pole regions during the southern hemispheric winter. The AMSU Ch9 Tbs from N15, N16, and N18 in the South Pole regions are biased 0.67 to $2 \mathrm{~K}$ lower than those from COSMIC. The temperature-dependent biases found here may be due to the fact that the raw AMSU data compared here use only pre-launch calibration coefficients, which may not account for the nonlinear calibration effect (Zou et al. 2006). More investigation regarding the causes of biases between operational calibrated L1B data to that derived from GPS RO data over the Antarctic during the southern hemispheric winter will be carried out in a future study. The seasonal variation of NOAA-COSMIC Tb biases at different geographical locations will also be investigated.

3. We demonstrate the potential of using GPS RO data to calibrate AMSU Ch8 and Ch10 Tbs in this study, where their weighting functions cover mainly the altitude ranging from 5 and $30 \mathrm{~km}$, but peak around $100 \mathrm{hPa}$ lower and $50 \mathrm{hPa}$ higher than that of AMSU Ch9, respectively. Because a very small portion of AMSU Ch8 and Ch10 WFs are covering above $10 \mathrm{hPa}$ (for AMSU Ch10) and below $500 \mathrm{hPa}$ (for AMSU Ch8), the effect of the uncertainty of GPS RO dry temperature above $10 \mathrm{hPa}$ and below $500 \mathrm{hPa}$ to the synthetic AMSU Tbs is negligible.

4. In this study, we also demonstrate the long-term stability between COSMIC and CHAMP dry temperature profiles. The CHAMP and COSMIC dry temperature difference between 500 and $10 \mathrm{hPa}$ ranges from $-0.35 \mathrm{~K}$ (at $10 \mathrm{hPa}$ ) to $0.25 \mathrm{~K}$ (at $30 \mathrm{hPa}$ ) and their mean difference estimated here is $-0.034 \mathrm{~K}$. This shows the usefulness for GPS RO data to serve as a climate benchmark to calibrate other satellite data. In the near future, we will use more COSMIC-CHAMP pairs to confirm the mission independent stability of GPS RO data.

5. In order to demonstrate the potential use of GPS RO calibrated AMSU Tbs to calibrate other temporally and spatially overlapped AMSU Tbs, we examine the robustness of the calibration coefficients (slope and offset) 
found from NOAA-GPS RO pairs. In this study, we quantify the accuracy of the defined slope and offset by evaluating the difference between COSMIC calibrated N18 AMSU Tbs ( Tb $\left._{\text {COSMIC_N18 }}\right)$ and CHAMP calibrated N18 AMSU Tbs ( $\left(\mathrm{Tb}_{\text {CHAMP }}\right.$ N18 $)$. Here the slope and offset of $\mathrm{Tb}_{\text {COSMIC N18 }}$ are defined using COSMIC-N18 pairs and the $\mathrm{Tb}_{\text {CHAMP }} 18$ used here are computed using N18 Tbs from CHAMP-N18 pairs. The purpose of evaluating the difference between $\mathrm{Tb}_{\text {COSMIC_N18 }}$ and $\mathrm{Tb}_{\text {CHAMP_N18 }}$ is to assess whether the slope and offset defined from COMSIC-N18 pairs are still valid when different N18 Tbs are used as inputs. Comparison results show that the correlation coefficient of $\mathrm{Tb}_{\text {CHAMP N18 }}$ and $\mathrm{Tb}_{\text {COSMIC N18 }}$ is equal to 1.0. The differences between $\mathrm{Tb}_{\mathrm{COSMIC}} \mathrm{AmsU}$ and $\mathrm{Tb}_{\text {CHAMP_AMSU }}$ are in the range of $\pm 0.07 \mathrm{~K}$ with standard deviation of about $0.1 \mathrm{~K}$. This demonstrates the robustness of the calibration coefficients found from NOAA-GPS RO pairs and shows the potential usage of the calibrated AMSU Tbs to inter-calibrate other overlapping AMSU Tbs where there are no coincident GPS RO data available. The consistency of the slope and offset from COSMIC-NOAA pairs to that from CHAMPNOAA pairs demonstrates that even with fewer samples (for example, CHAMP-N16 pairs in September 2006), due to the high precision of GPS RO data, we can still define robust slope and offset from NOAA-CHAMP pairs that is consistent with those from NOAA-COSMIC pairs.

6. The $\mathrm{Tb}_{\mathrm{COSMIC} A \mathrm{AMSU}}$ and $\mathrm{Tb}_{\mathrm{CHAMP}}{ }_{\text {AMSU }}$ comparison can also be interpreted as the indirect estimate of the precision of synthetic COSMIC $\mathrm{Tbs}\left(\mathrm{Tb}_{\mathrm{COSMIC}}\right)$ and that from CHAMP ( $\mathrm{Tb}_{\text {СнамP }}$ ) where NOAA AMSU Tbs are used as a cross reference. The estimated mean difference is in the range of $\pm 0.07 \mathrm{~K}$ of GPS RO-NOAA pairs with $\sim 0.1 \mathrm{~K}$ of standard deviation. The $\pm 0.07 \mathrm{~K}$ mean differences of GPS RO-NOAA pairs and $\sim 0.1 \mathrm{~K}$ of standard deviation may still be related to natural variability within $50 \mathrm{~km}$ separation distance and 30-minute time difference. In the future, more samples with smaller time differences and separation distance will be used to provide better estimation of the mean difference and precision between COSMIC and CHAMP data.

In this study, to minimize the impacts of ionosphere residual errors and lower level moisture effects on dry temperature retrievals, we use only measurements from AMSU Ch8, 9, and 10. For these measurements, the atmospheric contribution comes mainly from 5 to $35 \mathrm{~km}$. In the future we will explore the possibility of using GPS RO data to simulate other AMSU channels above $35 \mathrm{~km}$ and below $5 \mathrm{~km}$. With the penetration of COSMIC deep into the troposphere using an open-loop tracking algorithm, especially over relatively dry polar regions, the use of COSMIC data to calibrate AMSU channels whose weighting functions peak at upper to middle troposphere should be possible.

The robustness of the calibration coefficients found from GPS RO-NOAA pairs depends not only on the precision of GPS RO data, but also on the accuracy of the microwave forward model. Although the tight fit between synthetic GPS RO Tbs and observed AMSU Tbs demonstrates the feasibility of $\mathrm{MWF}_{\mathrm{CIMSS}}$ used here, for the purpose of climate studies it is still very important to identify the uncertainty of the transmittances used in $\mathrm{MWF}_{\mathrm{CIMSS}}$ for various atmospheric conditions. In the future, we will also use AMSU/MSU measurements from various NOAA satellites to collocate with COSMIC GPS RO sounding to minimize the spatial and temporal separation of COSMIC-AMSU matches. Different AMSU and MSU data will be calibrated using consistent COSMIC soundings. Consistent AMSU and MSU weighting functions will be used. Sampling uncertainties will be significantly reduced when around 8 to 10 times more GPS RO soundings than CHAMP data are available from COSMIC for comparison. Consistent and long-term stable observations from AMSU/MSU data from different satellite missions for climate change can then be constructed.

Acknowledgements We would like to thank Mr. Hal Woolf from the Cooperative Institution for Meteorological Satellite Studies for providing the fast AMSU Forward Transfer Algorithm package. The help in setting up AMSU/ MSU reading programs from Dr. Jiang Zhao from NOAA is much appreciated. We would also like to acknowledge the contributions to this work from members of the COSMIC team at UCAR and members of satellite operational team at the National Space Organization, Taiwan.

\section{REFERENCES}

Angell, J. K., 1988: Variations and trends in tropospheric and stratospheric global temperatures, 1958-87. J. Climate, 1, 1296-1313, doi: 10.1175/1520-0442(1988)001<1296: VATITA $>2.0 . \mathrm{CO} ; 2$. [Link $]$

Christy, J. R. and W. B. Norris, 2004: What may we conclude about global tropospheric temperature trends? Geophys. Res. Lett., 31, L06211, doi: 10.1029/2003GL019361. [Link]

Christy, J. R., R. W. Spencer, and E. S. Lobel, 1998: Analysis of the merging procedure for the MSU daily temperature time series. J. Climate, 11, 2016-2041, doi: 10.1175/1520-0442 (1998)011<2016:AOTMPF>2.0.CO;2. [Link]

Christy, J. R., R. W. Spencer, and W. D. Braswell, 2000: MSU Tropospheric temperatures: Data set construction and radiosonde comparisons. J. Atmos. Ocean. Technol., 17, 1153-1170, doi: 10.1175/1520-0426(2000)017<1153: MTTDCA $>2.0 . C O ; 2$. [Link]

Christy, J. R., R. W. Spencer, W. B. Norris, W. D. Braswell, and D. E. Parker, 2003: Error estimates of Version 5.0 of MSU/ AMSU bulk atmospheric temperatures. J. Atmos. Ocean. Technol., 20, 613-629, doi: 10.1175/1520-0426(2003)20 
$<613$ :EEOVOM $>2.0 . \mathrm{CO}$;2. [Link]

Feng, D. D. and B. M. Herman, 1999: Remotely sensing the Earth's atmosphere using the Global Positioning System (GPS)-The GPS/MET data analysis. J. Atmos. Ocean. Technol., 16, 989-1002., doi: 10.1175/1520-0426(1999) 016<0989:RSTESA $>2.0 . C O ; 2$. [Link]

Folland, C. K. and Coauthors, 2001: Observed climate variability and change. In: Houghton, J. T. et al. (Eds.), Climate Change, 2001: The Scientific Basis, Cambridge University Press, 99-181.

$\mathrm{Fu}, \mathrm{Q}$. and C. M. Johanson, 2004: Stratospheric influence on MSU-derived Tropospheric temperature trends: A direct error analysis. J. Climate, 17, 4636-4640, doi: 10.1175/ JCLI-3267.1. [Link]

Gaffen, D. J., M. A. Sargent, R. E. Habermann, and J. R. Lanzante, 2000: Sensitivity of tropospheric and stratospheric temperature trends to radiosonde data quality. $J$. Climate, 13, 1776-1796, doi: 10.1175/1520-0442(2000) 013<1776:SOTAST $>2.0$. CO;2. [Link]

Gobiet, A., U. Foelsche, A. K. Steiner, M. Borsche, G. Kirchengast, and J. Wickert, 2005: Climatological validation of stratospheric temperature in ECMWF operational analyses with CHAMP radio occultation data. Geophys, Res. Lett., 32, L12806, doi: 10.1029/2005GL022617. [Link]

Grody, N. C., K. Y. Vinnikov, M. D. Goldberg, J. Sullivan, and J. D. Tarpley, 2004: Calibration of Multi-satellites observations for climate studies, Microwave Sounding Unit (MSU). J. Geophys. Res., 109, doi: 10.1029/2004 JD005079. [Link]

Hajj, G., C. O. Ao, B. A. Iijima, D. Kuang, E. R. Kursinski, A. J. Mannucci, T. K. Meehan, L. J. Romans, M. de la Torre Juarez, and T. P. Yunck, 2004: CHAMP and SAC-C atmospheric occultation results and inter-comparisons. J. Geophys. Res., 109, D06109, doi: 10.1029/2003JD003909. [Link]

Ho, S. P., Y. H. Kuo, Z. Zeng, and T. Peterson, 2007: A comparison of lower stratosphere temperature from microwave measurements with CHAMP GPS RO data. Geophys. Res. Lett., 34, L15701, doi: 10.1029/2007GL030202. [Link]

Hocke, K., 1997: Inversion of GPS meteorology data. Ann. Geophys., 15, 443-450, doi: 10.1007/s00585-997-0443-1. [Link]

Kuo, Y. H., T. K. Wee, S. Sokolovskiy, C. Rocken, W. Schreiner, D. Hunt, and R. A. Anthes, 2004: Inversion and error estimation of GPS radio occultation data. J. Meteorol. Soc. Jpn., 82, 507-531, doi: 10.2151/jmsj.2004.507. [Link]

Kuo, Y. H., W. S. Schreiner, J. Wang, D. Rossiter, and Y. Zhang, 2005: Comparison of GPS radio occultation soundings with radiosondes. Geophys. Res. Lett., 32, L05817, doi: 10.1029/2004GL021443. [Link]

Kursinski, E. R., G. A. Hajj, J. T. Schofield, R. Linfield, and K. R. Hardy, 1997: Observing earth's atmosphere with radio occultation measurements. J. Geophys. Res., 102, 2342923465, doi: 10.1029/97JD01569. [Link]

Mears, C. A., F. J. Wentz, 2005: The effect of diurnal correction on satellite-derived lower tropospheric temperature. Science, 309, 1548-1551, doi: 10.1126/science.1114772. [Link]

Mears, C. A., M. C. Schabel, and F. J. Wentz, 2003: A reanalysis of the MSU channel 2 tropospheric temperature record. $J$. Climate, 16, 3650-3664, doi: 10.1175/1520-0442(2003) $016<3650$ :AROTMC $>2.0 . C O ; 2$. [Link]

Melbourne, W. G., E. S. Davis, C. B. Duncan, G .A. Hajj, K. R. Hardy, E. R. Kursinski, T. K. Meehan, L. E. Young, and T. P. Yunck, 1994: The application of spaceborne GPS to atmospheric limb sounding and global change monitoring. JPL Publ., 94-18, 147 pp.

Rocken, C., R. Anthes, M. Exner, D. Hunt, S. Sokolovskiy, R. Ware, M. Gorbunov, W. Schreiner, D. Feng, B. Herman, Y. H. Kuo, and X. Zou, 1997: Analysis and validation of GPS/MET data in the neutral atmosphere. J. Geophys. Res., 102, 29849-29866, doi: 10.1029/97JD02400. [Link]

Santer, B. D., T. M. L. Wigley, C. Mears, F. J. Wentz, S. A. Klein, D. J. Seidel, K. E. Taylor, P. W. Thorne, M. F. Wehner, P. J. Gleckler, J. S. Boyle, W. D. Collins, K. W. Dixon, C. Doutriaux, M. Free, Q. Fu, J. E. Hansen, G. S. Jones, R. Ruedy, T. R. Karl, J. R. Lanzante, G. A. Meehl, V. Ramaswamy, G. Russell, and G. A. Schmidt, 2005: Amplification of surface temperature trends and variability in the tropical atmosphere. Science, 309, 1551-1556, doi: 10.1126/science.1114867. [Link]

Schmidt, T., J. Wickert, G. Beyerle, and C. Reigber, 2004: Tropical tropopause parameter derived from GPS radio occultation measurements with CHAMP. J. Geophys. Res., 109, D13105, doi: 10.1029/2004JD004566. [Link]

Schreiner, W., C. Rocken, S. Sokolovskiy, S. Syndergaard, and D. Hunt, 2007: Estimates of the precision of GPS radio occultations from the COSMIC/FORMOSAT-3 mission. Geophys. Res. Lett., 34, L04808, doi: 10.1029/2006GL 027557. [Link]

Schroeder, T., S. Leory, M. Stendel, and E. Kaas, 2003: Validating the microwave sounding unit stratospheric record using GPS occultation. Geophys. Res. Lett., 30, 1734, doi: 10.1029/2003GL017588. [Link]

Sherwood, S. C., J. R. Lanzante, and C. L. Meyer, 2005: Radiosonde daytime biases and late- $20^{\text {th }}$ Century warming. Science, 309, 1556-1559, doi: 10.1126/science.1115640. [Link]

Sokolovskiy, S., C. Rocken, D. Hunt, W. Schreiner, J. Johnson, D. Masters, and S. Esterhuizen, 2006: GPS profiling of the lower troposphere from space: Inversion and demodulation of the open-loop radio occultation signals. Geophys. Res. Lett., 33, L14816, doi: 10.1029/2006GL026112. [Link]

Spencer, R. W. and J. R. Christy, 1992a: Precision and radiosonde validation of satellite gridpoint temperature anomalies. Part I: MSU Channel 2. J. Climate, 5, 847-857, doi: 10.1175/1520-0442(1992)005<0847:PARVOS >2.0.CO;2. [Link] 
Spencer, R. W. and J. R. Christy, 1992b: Precision and radiosonde validation of satellite gridpoint temperature anomalies. Part II: A tropospheric retrieval and trends during 1979-90. J. Climate, 5, 858-866, doi: 10.1175/1520-0442 (1992)005<0858:PARVOS>2.0.CO;2. [Link]

Steiner, A. K., G. Kirchengast, and H. P. Ladreiter, 1999: Inversion, error analysis, and validation of GPS/MET occultation data. Ann. Geophys., 17, 122-138, doi: 10. 1007/s005850050742. [Link]

Vinnikov, K. Y. and N. C. Grody, 2003: Global warming trend of mean tropospheric temperature observed by satellites. Science, 302, 269-272, doi:10.1126/science.1087910. [Link]

Vinnikov, K. Y., N. Grody, A. Robock, R. J. Stouffer, P. D. Jones, and M. D. Goldberg, 2006: Temperature trends at the surface and in the troposphere. J. Geophys. Res., 111, D03106, doi: 10.1029/2005JD006392. [Link]

Ware, R., C. Rocken, F. Solheim, M. Exner, W. Schreiner, R. Anthes, D. Feng, B. Herman, M. Gorbunov, S. Sokolovskiy, K. Hardy, Y. H. Kuo, X. Zou, K. Trenberth, T. Meehan, W. Melbourne, and S. Businger, 1996: GPS Sounding of the atmosphere from low Earth orbit: Prelimi- nary results. Bull. Amer. Meteor. Soc., 77, 19-40, doi: 10.1175/1520-0477(1996)077<0019:GSOTAF>2.0.CO;2. [Link]

Wickert, J., T. Schmidt, G. Beyerle, R. Konig, C. Reigber, and N. Jakowski, 2004: The radio occultation experiment aboard CHAMP: Operational data analysis and validation of vertical atmospheric profiles. J. Meteorol. Soc. Jpn., 82, 381-395, doi: 10.2151/jmsj.2004.381. [Link]

Woolf, H., P. van Delst, W. Zhang, 1999: NOAA-15 HIRS/3 and AMSU transmittance model validation. Technical Proceedings of the International ATOVS Study Conference, 10th, Boulder, CO, 27 January-2 February 1999. Bureau of Meteorology Research Centre, Melbourne, Australia, 564-573

Yunck, T., C. H. Liu, and R. Ware, 2000: A history of GPS sounding. Terr. Atmos. Ocean. Sci., 11, 1-20.

Zou, C., M. D. Goldberg, Z. Cheng, N. C. Grody, J. T. Sullivan, C. Cao, and D. Tarpley, 2006: Recalibration of microwave sounding unit for climate studies using simultaneous nadir overpasses. J. Geophys. Res., 111, D19114, doi: 10.1029/ 2005JD006798. [Link] 